\title{
From isolation to application: a case study of arbuscular mycorrhizal fungi of the Arabian Peninsula
}

\author{
Mohamed N. Al-Yahya'ei ${ }^{1,2,3,4} \cdot$ Janusz Błaszkowski ${ }^{5} \cdot$ Hamood Al-Hashmi ${ }^{2} \cdot$ Khaled Al-Farsi ${ }^{6} \cdot$ Ismail Al-Rashdi $^{6}$. \\ Annette Patzelt ${ }^{6} \cdot$ Thomas Boller $^{1} \cdot$ Andres Wiemken $^{1} \cdot$ Sarah Symanczik ${ }^{1,7}$
}

Received: 16 August 2021 / Accepted: 19 November 2021 / Published online: 8 December 2021

(c) The Author(s) 2021

\begin{abstract}
The vegetation in the Arabian Peninsula experiences drought, heat, soil salinity, and low fertility, mainly due to low phosphorus (P) availability. The beneficial mycorrhizal symbiosis between plants and arbuscular mycorrhizal fungi (AMF) is a key factor supporting plant growth under such environmental conditions. Therefore, AMF strains isolated from these soils might be useful as biotechnological tools for agriculture and revegetation practices in the region. Here we present a pioneering program to isolate, identify, and apply AMF isolated from rhizosphere soils of agricultural and natural habitats, namely date palm plantations and five native desert plants, respectively in the Southern Arabian Peninsula. We established taxonomically unique AMF species as single-spore cultures as part of an expanding collection of AMF strains adapted to arid ecosystems. Preliminary experiments were conducted to evaluate the abilities of these AMF strains to promote seedling growth of a main crop Phoenix dactylifera L. and a common plant Prosopis cineraria L. (Druce) in the Arabian Peninsula. The results showed that inoculation with certain AMF species enhanced the growth of both plants, highlighting the potential of these fungi as part of sustainable land use practices in this region.
\end{abstract}

Keywords Date palm $\cdot$ Desert ecosystem $\cdot$ Mycorrhizal symbiosis $\cdot$ Oman $\cdot$ Native plants

Sarah Symanczik

sarah.symanczik@fibl.org

1 Zurich Basel Plant Science Center, Institute of Botany, University of Basel, Hebelstrasse 1, CH-4056 Basel, Switzerland

2 Directorate General of Agricultural and Livestock Research, Ministry of Agriculture, Fisheries and Water Resources, P. O. Box 50, P.C. 121, Muscat, Sultanate of Oman

3 Department of Integrative Agriculture, College of Agriculture and Veterinary Medicine, United Arab Emirates University, 15551, Al Ain, United Arab Emirates

4 Oman Animal and Plant Genetic Resources Center (Mawarid), Ministry of Higher Education, Research and Innovation, P.O. Box 515, P.C. 123, Muscat, Sultanate of Oman

5 Department of Plant Protection, West Pomeranian University of Technology, Szczecin, Slowackiego 17, 71434 Szczecin, Poland

6 Oman Botanic Garden, P. O. Box 808, P.C. 122, Muscat, Sultanate of Oman

7 Research Institute of Organic Agriculture (FiBL), Ackerstrasse 113, 5070 Frick, Switzerland

\section{Introduction}

The application of arbuscular mycorrhizal fungal (AMF) inocula in agriculture and revegetation programs has recently become more prominent, largely due to the increasing number of studies demonstrating improved plant growth after inoculation (Igiehon and Babalola 2017; Bano and Uzair 2021). The application of AMF inocula at the nursery stage in horticulture is especially beneficial as it provides the plants with an established, tailored AM symbiosis before they are transplanted in the field (Nzanza et al. 2012; Ren et al. 2019). Hence, colonization of the soil by fungal hyphae can start immediately (Jeffries et al. 2003). AMF hyphae have been shown to be important infection structures in arid and semi-arid ecosystems (Requena et al. 1996; AzcónAguilar et al. 2003). Therefore, the application of AMF in the nursery increases the infectivity of soils in such habitats (Requena et al. 2001).

AMF species or strains adapted to distinct environmental conditions have been described previously (Marulanda et al. 2007; Lekberg and Koide 2008; Antunes et al. 2011). Antunes et al. (2011) observed that AMF exhibit optimal 
performance in experimental conditions that closely resemble the environmental conditions from where they were derived. Moreover, Bauer et al. (2020) have shown that plant community productivity responded positively to local adaptation of AMF to soil conditions yielding in higher aboveground biomass. Further, it has been shown that inoculation with exotic AMF may disturb the structure of native AMF communities (Mummey et al. 2009; Koch et al. 2011; Symanczik et al. 2015). Therefore, possible changes in native AMF communities via invasion of exotic ones should be considered to assess the risk of future unintended consequences (Schwartz et al. 2006).

Here, we describe the establishment of a culture collection of single-spore derived AMF strains, originally recovered from different habitats and a variety of native plant species in Oman (Al-Yahya'ei et al. 2011; Symanczik et al. 2014a, b). The AMF culture collection provides a crucial basis for mycorrhizal research under the harsh conditions of the Southern Arabian Peninsula (Symanczik et al. 2015), which is also an environmentally unique landscape (Fisher and Membery 1998; Glennie and Singhvi 2002).

Two plant species, Phoenix dactylifera L. (date palm) and Prosopis cineraria L. (Druce) (local name: Ghaf) were selected for inoculation with AMF species from the culture collection. Date palm is the main crop in Arabia and in many other desert areas of the world (Zaid and De Wet 2002), and is considered a survival crop due to the high nutritional value of its fruit (Al-Shahib and Marshall 2003). P. cineraria is a tree native to the Arabian Peninsula, Iran, Afghanistan, Pakistan, and India, and plays an important role as an agroforestry species as it forms a tripartite symbiosis with AMF and rhizobial nitrogen-fixing bacteria.

The aims of this study were to isolate, identify, propagate, and functionally evaluate the AMF from agricultural and natural habitats in the Southern Arabian Peninsula. Such an approach can help integrate efficient and native AMF strains into sustainable agriculture and revegetation programs on the Arabian Peninsula.

\section{Materials and methods}

\subsection{Establishment of the AMF culture collection}

The isolated species of AMF recovered from the Al-Sharqiya region of Oman are listed in Table 1. Four sites were sampled. Two sites were date palm plantations that were established on a sandy plain. Management followed local traditional farming practices at one site and modern agriculture practices at the other. A ruderal plant, Polygala erioptera

Table 1 Number of arbuscular mycorrhizal fungal (AMF) single-spore-derived cultures in relation to their original host plants and the host plants' habitat

\begin{tabular}{|c|c|c|c|}
\hline AMF species & Associated plant species & Habitat & $\begin{array}{l}\text { Number } \\
\text { of AMF } \\
\text { cultures }\end{array}$ \\
\hline Claroideoglomus drummondii & $\begin{array}{l}\text { Tetraena qatarense } \\
\text { Salvadora persica } \\
\text { Prosopis cineraria } \\
\text { Inter-plant area }\end{array}$ & Undisturbed habitat & $\begin{array}{l}1 \\
6 \\
8 \\
8\end{array}$ \\
\hline Desertispora omaniana & $\begin{array}{l}\text { Tetraena qatarensis } \\
\text { Salvadora persica } \\
\text { Inter-plant area }\end{array}$ & Undisturbed habitat & $\begin{array}{l}1 \\
1 \\
2\end{array}$ \\
\hline Diversispora aurantia & $\begin{array}{l}\text { Prosopis cineraria } \\
\text { Phoenix dactylifera }\end{array}$ & $\begin{array}{l}\text { Undisturbed habitat } \\
\text { Traditional date palm plantation }\end{array}$ & $\begin{array}{l}3 \\
3\end{array}$ \\
\hline Diversispora spurca & $\begin{array}{l}\text { Tetraena qatarensis } \\
\text { Salvadora persica } \\
\text { Prosopis cineraria } \\
\text { Inter-plant area } \\
\text { Heliotropium bacciferum } \\
\text { Polygala erioptera } \\
\text { Phoenix dactylifera } \\
\text { Phoenix dactylifera }\end{array}$ & $\begin{array}{l}\text { Undisturbed habitat } \\
\text { Undisturbed habitat } \\
\text { Undisturbed habitat } \\
\text { Undisturbed habitat } \\
\text { Sand dunes } \\
\text { Undisturbed habitat } \\
\text { Modern date palm plantation Traditional } \\
\text { date palm plantation }\end{array}$ & $\begin{array}{l}9 \\
16 \\
4 \\
3 \\
3 \\
4 \\
1 \\
3\end{array}$ \\
\hline Pervetustus simplex & $\begin{array}{l}\text { Tetraena qatarense } \\
\text { Salvadora persica }\end{array}$ & Undisturbed habitat & $\begin{array}{l}3 \\
2\end{array}$ \\
\hline Rhizophagus arabicus & Inter-plant area & Undisturbed habitat & 2 \\
\hline Septoglomus africanum & Phoenix dactylifera & Traditional date palm plantation & 4 \\
\hline Septoglomus nakheelum & Phoenix dactylifera & Traditional date palm plantation & 3 \\
\hline Total number of AMF cultures & & & 90 \\
\hline
\end{tabular}


DC, growing on the dry strip between the palm trees at the modern agriculture site was also included in the sampling. A third sampled site was an undisturbed habitat adjacent to the modern date palm plantation. The natural vegetation of this habitat consisted mainly of three perennial plant species, Tetraena qatarensis, Salvadora persica L., and Prosopis cineraria, and open vegetation with dispersed patches of dry grass apparently growing after rainfall. The fourth sampling site was in the Al-Sharqiya Sands, a large sand desert in northern Oman (Patzelt 2015). A native plant, Heliotropium bacciferum Forssk., growing in this habitat was included in the samples. The geography of the region, sampled sites, environmental conditions, and soil properties are described in Al-Yahya'ei et al. (2011) and Symanczik et al. (2014a, b). Trap cultures were established in each of the four sampling sites to collect soil and root samples of plants. The trap cultures and greenhouse conditions for subsequent cultures have been described previously (Al-Yahya'ei et al. 2011).

\subsection{Inocula preparation and identification}

Freshly produced spores from the trap cultures were used to established more than 1000 single-spore assays to derive single-spore cultures, as described previously (Symanczik et al. 2014a, b). Single-spore assays were checked for sporulation, and positive cultures were used as inocula for further propagation by culturing with a consortium of Allium porrum L., Hieracium pilosella L., and Plantago lanceolata $\mathrm{L}$. as AMF host plants. The resulting mycorrhizal inocula were identified using morphological and molecular identification methods, as described previously (Symanczik et al. 2014a, b; Blaszkovski et al. 2017; Symanczik et al. 2018).

\subsection{Inoculation of date palm}

The date palm inoculation experiment was conducted in the Agricultural Research Station of Jemah, Oman Ministry of Agriculture, Fisheries and Water Resources. The date palm seedlings (Khalas Al Daherah variety) were tissue-cultured. Seedlings were established for 28 months at the callus stage under tissue culture conditions, then transplanted into 100$\mathrm{mL}$ pots filled with peat moss (Plantafior, Germany) and vermiculite $(1: 1 ; \mathrm{v} / \mathrm{v})$ and grown for 5 months in a shade house (temperature: $24-32{ }^{\circ} \mathrm{C}$; relative humidity: $65-70 \%$ ). Date palm seedlings for the experiment were selected based on their homogeneity of total height and leaf number. Six AMF strains were used as single-species inocula, Diversispora aurantia (strain G8), Septoglomus africanum (strain G14), Claroideoglomus drummondii (strain F41), Desertispora omaniana (strain F69), Pervetustus simplex (strain C49), and $P$. simplex (strain C57). One consortium inoculum that included all five species was also used. The inocula, added as substrate inocula, included a total of 250 spores and a volume of $15 \mathrm{~g}$ pre-weighed into $15 \mathrm{ml}$ reaction tubes. Those single-strain inocula with high spore numbers were diluted with sterilized inocula to reach a total volume of $15 \mathrm{~g}$. While transplanting the seedlings into 3 -L plastic bags filled with peat moss (Plantafior, Germany) and vermiculite $(1: 1 ; \mathrm{v} / \mathrm{v})$ the inocula was homogeneously spread onto the root system. Two controls were included: a non-mycorrhizal (NM) control, to which no AMF inoculum was added, and a non-mycorrhizal fertilized (NM-fert) control that was the only treatments receiving foliar-fertilizer (Micromix X200 SP, Pioneers Chemicals Factory CO, SA) weekly. The latter represented the conventional handling practice of date palm seedlings at the Research Station. Plant growth performance after 12 months was estimated by measuring the total lengths of all leaves of a single plant (accumulated length of all leaves as an estimate of biomass) and the number of leaves. No destructive harvest was performed as plants were later transplanted to the field.

\subsection{Inoculation of P. cineraria}

The inoculation experiment was conducted at the Oman Botanic Garden (www.omanbotanicgarden.com; Patzelt et al. 2008). P. cineraria seeds were soaked in water overnight before being sown in compartmented germination trays. Each seed was placed in a 50-mL pot filled with a mixture of peat moss (Plantafior, Germany) and vermiculite (1:1; $\mathrm{v} / \mathrm{v})$ and supplemented either with mycorrhizal inocula or one of the control treatments. Seven single-species inocula were used, P. simplex (strain C49), Septoglomus nakheelum (strain G90), Di. spurca (strain K46), Rhizophagus arabicus (strain F80), De. omaniana (strain F69), Di. aurantia (strain G5), and S. africanum (strain G14). In addition, four different consortia were used as inocula. These were consortium 1 (P. simplex strain C49 and C56), consortium 2 (C. drummondii strain F41 and De. omaniana strain F69), consortium 3 (S. africanum strain G14 and De. omaniana strain F69), and consortium 4 ( $P$. simplex strain C49, C. drummondii strain F41, S. africanum strain G41, and De. omaniana strain F69). Additionally, four non-mycorrhizal control treatments were applied: microbial wash (control 1), autoclaved inoculum carrier (control 2), microbial wash and autoclaved inoculum carrier (control 3), and a negative control (control 4). Eight seeds were used as replicates for mycorrhizal treatments and 20 seeds for the control treatments. Higher numbers of seeds in the control treatments were used as there were low germination rates in preliminary experiments (data not shown). For inoculation, $5 \mathrm{~g}$ of substrate inocula containing a total of 250 spores was homogeneously mixed into the growing substrate using a sterile spatula. Those single-strain inocula with high spore numbers were diluted with sterilized inocula to reach a total volume of $5 \mathrm{~g}$. Each pot, except control 2 and control 4 , received $5 \mathrm{~mL}$ of the microbial wash to correct 
possible differences in microbial communities (Koide and Elliott 1989). The microbial wash was prepared by wetsieving $100 \mathrm{~g}$ of each inoculum through a 32- $\mu \mathrm{m}$ sieve and a paper filter (FS 14 1/2; Schleicher \& Schuell, Whatman plc, United Kingdom), yielding a final volume of 1 L. After 1 month, seedlings were transplanted into $300-\mathrm{mL}$ pots filled with a mixture of original soil from the surrounding area of the Botanic Garden and fine peat moss (1:1; v/v), and grown for 2 months under greenhouse conditions (temperature: 25-28 ${ }^{\circ} \mathrm{C}$; relative humidity: $60-70 \%$ ). Pots were placed on a greenhouse bench and carefully irrigated by hand to avoid contamination between treatments.

Germination rates were calculated as the percentage of surviving seedlings divided by the initial number of seeds sown (Table 2). Plant growth performance was estimated 3 months after sowing by measuring the total length of all branches of a single plant (accumulated length of all branches as an estimate of total biomass). Survival rates were calculated as the percentage of seedlings present after 12 months divided by the number of germinated seedlings. No destructive harvest was performed as plants were later transplanted to the field.

\subsection{Statistical analyses}

Data were analyzed using one-way ANOVA followed by Tukey's honest significant difference test with a significance level of a D 0.05. Normality of residuals was tested using
Shapiro-Wilk test. Analyses were performed using JMP software version 11 (SAS, Cary, NC, United States).

\section{Results \& Discussion}

\subsection{Establishment of the AMF culture collection}

Of more than 1000 single-spore assays, only 90 single-spore derived cultures were successfully established. Amongst them, eight different AMF species were identified. Four were already described AMF species, including Claroideoglomus drummondii, Diversispora aurantia, Diversispora spurca, and Septoglomus africanum (Symanczik et al. 2014b). However, four species were previously unknown. They were given names unique to the geographical region of the Southern Arabian Peninsula: Desertispora omaniana, Rhizophagus arabicus, Septoglomus nakheelum and Pervetustus simplex (Symanczik et al. 2014a; Blaszkovski et al. 2017). The phylogenetic and morphological characterization of all eight species is represented in Fig. 1. Numbers of established AMF single-spore cultures in relation to their original host plant species are shown in Table 1.

The importance and significance of establishing a culture collection specific to a target ecosystem has been previously demonstrated for degraded semi-arid Mediterranean ecosystems (Barea et al. 2011). Similar efforts were made at the Centre for Mycorrhizal Culture Collection (CMCC) which houses and maintains cultures from different agro-ecological
Table 2 Germination of seeds and survival of seedlings of Prosopis cineraria under different control and inoculation treatments

\begin{tabular}{|c|c|c|c|c|c|}
\hline \multirow[t]{2}{*}{ Arbuscular mycorrhizal fungal treatment } & \multirow[t]{2}{*}{$\begin{array}{l}\text { Initial seeds } \\
\text { treatment }^{-1}\end{array}$} & \multicolumn{2}{|c|}{ Germination of seeds } & \multicolumn{2}{|c|}{$\begin{array}{l}\text { Survival of seed- } \\
\text { lings }\end{array}$} \\
\hline & & Number & $\%$ & Number & $\%$ \\
\hline Control 1 & 40 & 7 & 18 & 7 & 100 \\
\hline Control 2 & 40 & 12 & 30 & 8 & 67 \\
\hline Control 3 & 40 & 13 & 33 & 7 & 54 \\
\hline Control 4 & 40 & 10 & 25 & 6 & 60 \\
\hline Pervetustus simplex strain C49 & 8 & 5 & 63 & 5 & 100 \\
\hline Septoglomus nakheelum & 8 & 5 & 63 & 5 & 100 \\
\hline Diversispora spurca & 8 & 5 & 63 & 5 & 100 \\
\hline Rhizophagus arabicus & 8 & 5 & 63 & 5 & 100 \\
\hline Desertispora omaniana & 8 & 5 & 63 & 5 & 100 \\
\hline Diversispora aurantia & 8 & 4 & 50 & 4 & 100 \\
\hline Septoglomus africanum & 8 & 7 & 88 & 7 & 100 \\
\hline Consortium 1 & 8 & 6 & 75 & 6 & 100 \\
\hline Consortium 2 & 8 & 3 & 38 & 3 & 100 \\
\hline Consortium 3 & 8 & 5 & 63 & 5 & 100 \\
\hline Consortium 4 & 8 & 4 & 50 & 4 & 100 \\
\hline
\end{tabular}

Consortium 1 ( $P$. simplex strain $\mathrm{C} 49$ and C56), consortium 2 (C. drummondii and De. omaniana), consortium 3 (S. africanum and De. omaniana), consortium 4 (P. simplex strain C49, C. drummondii, S. africanum, and De. omaniana), control 1 (microbial wash), control 2 (autoclaved inoculum carrier), control 3 (microbial wash and autoclaved inoculum carrier), control 4 (no amendments) 
Fig. 1 Phylogenetic positions and morphology of the eight arbuscular mycorrhizal fungal (AMF) species recovered from the Arabian Peninsula. The simplified phylogenetic tree was inferred from the partial LSU rDNA region (628 dataset characters), and shows the positions of the isolated AMF species (shown in colored boldface). An image of each of the AMF species is associated with its phylogenetic position. Sequences were aligned in PAUP*4b10 (Swofford 2001) to other sequences from GenBank of species within the same genera. The phylogenetic tree was inferred using maximum likelihood criteria as implemented in PAUP*

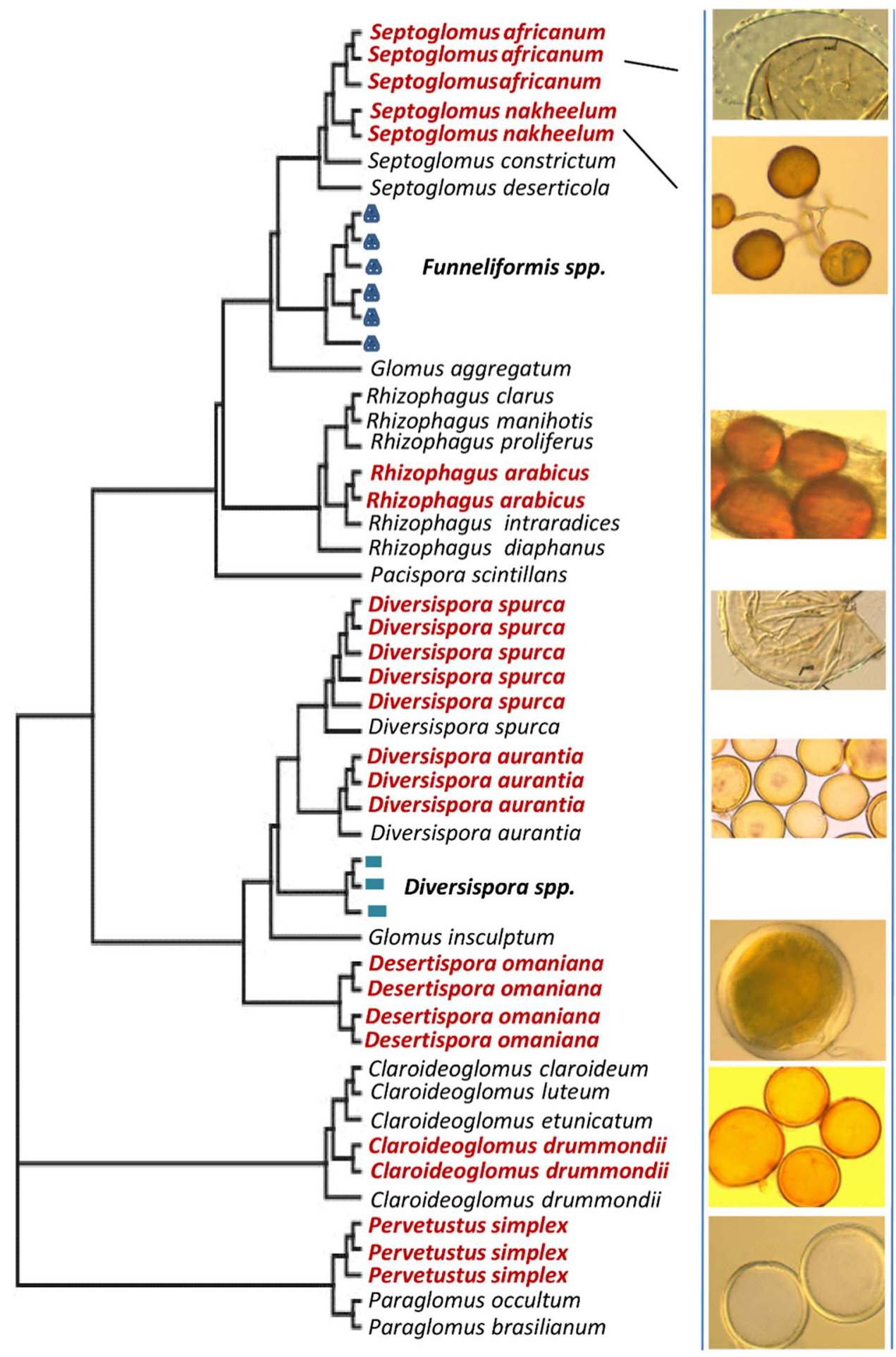

zones in India (TERI) and for AMF in China (Gai et al. 2006). Culture collections of AMF from specific ecosystems are fundamental to the process of applying these beneficial fungi in revegetation programs. Koziol et al. (2018) recently reviewed the potential and benefits of applying native AMF for restoration efforts with a focus on grasslands. The importance of native AMF as keystone taxa for revegetation was recently highlighted also by Qin et al. (2019). Their field study on the Tibetan plateau revealed the significance of AMF in enhancing bacterial and fungal richness and diversity, soil structure stability, and nutrients cycling.

In the Southern Arabian Peninsula, the Oman Botanic Garden holds the largest documented collection of Arabian plants in the world (Patzelt et al. 2008, 2009). The 
garden aims to propagate and display the complete indigenous flora of the Sultanate of Oman, and address the urgent need for conservation solutions to the biodiversity crisis. Mycorrhizal biotechnology might be a crucial factor to overcome the difficulties in propagation and maintenance of some indigenous plants.

\subsection{Growth performance of inoculated date palms}

The growth of date palm seedlings (total leaf length: $\mathrm{F}$ $(8,34)=5.9, \mathrm{P}>0.0001$; numbers of leaves: $\mathrm{F}(8,34)=4.3$, $\mathrm{P}=0.0012$ ) was significantly affected by AMF inoculation. The total leaf length of date palms were significantly higher for all AMF strains and the NM-fert control plants except $P$. simplex strain $\mathrm{C} 57$ and the consortium showing similar values as the NM-control plants (Fig. 2A and
Fig. 2 Effect of inoculation with arbuscular mycorrhizal fungi (AMF) on plant growth; (a) date palms grown as non-mycorrhizal control (left) and as mycorrhizal plants, inoculated with Diversispora aurantia (right); (b) Prosopis cineraria grown as non-mycorrhizal control (left) and as mycorrhizal plants, inoculated with Septoglomus africanum (right)

Fig. 3 Impact of inoculation with different arbuscular mycorrhizal fungal (AMF) species on (a) total leaf length and (b) the number of leaves of date palm seedlings. The consortium included all five AMF species: Diversispora aurantia, Septoglomus africanum, Claroideoglomus drummondii, Desertispora omaniana, and Pervetustus simplex. Different letters above bars indicate significant differences according to Tukey's honest significant difference test $(\mathrm{P} \leq 0.05)$. Data represent means \pm standard error $(\mathrm{n}=4-5)$
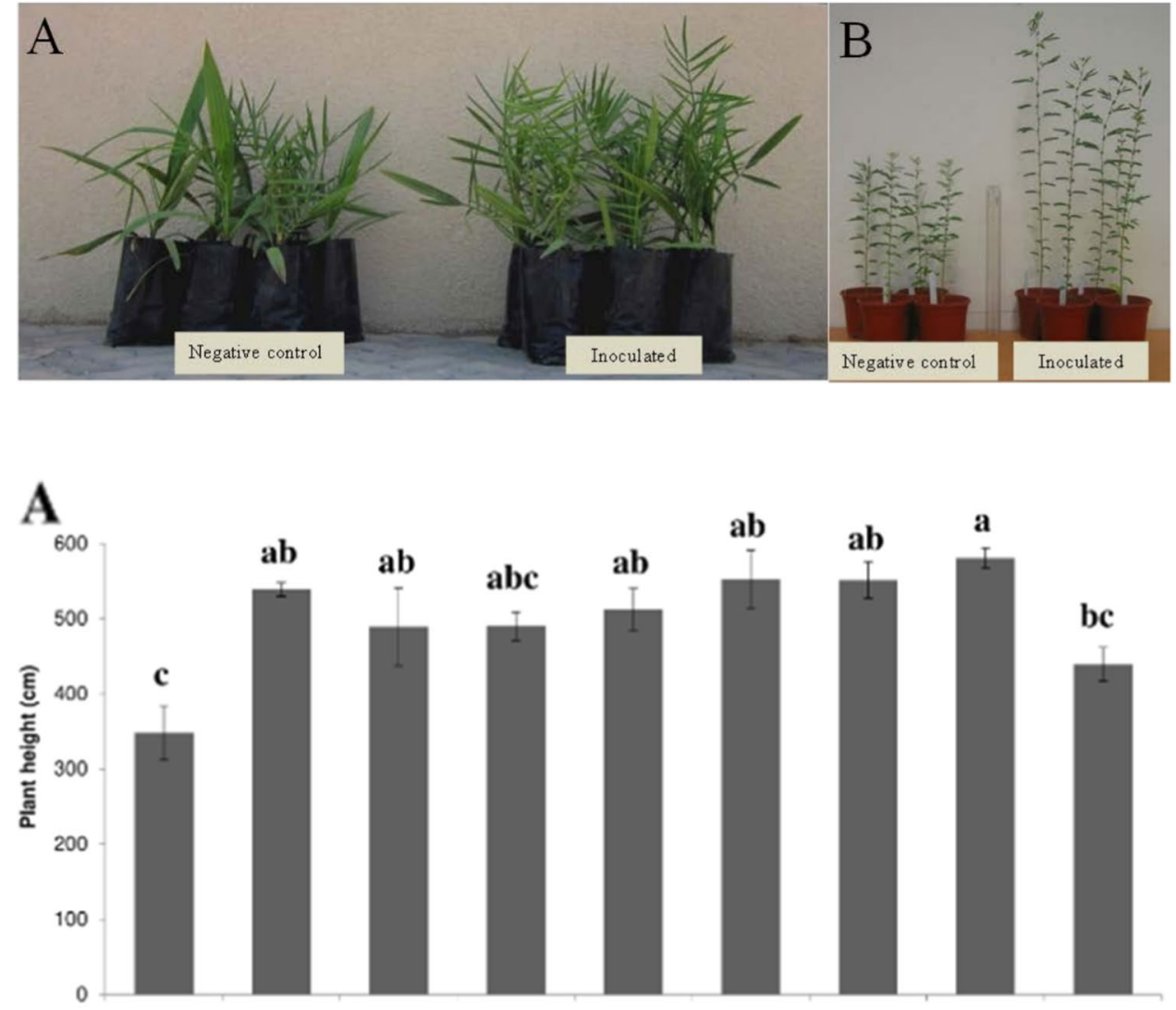

B

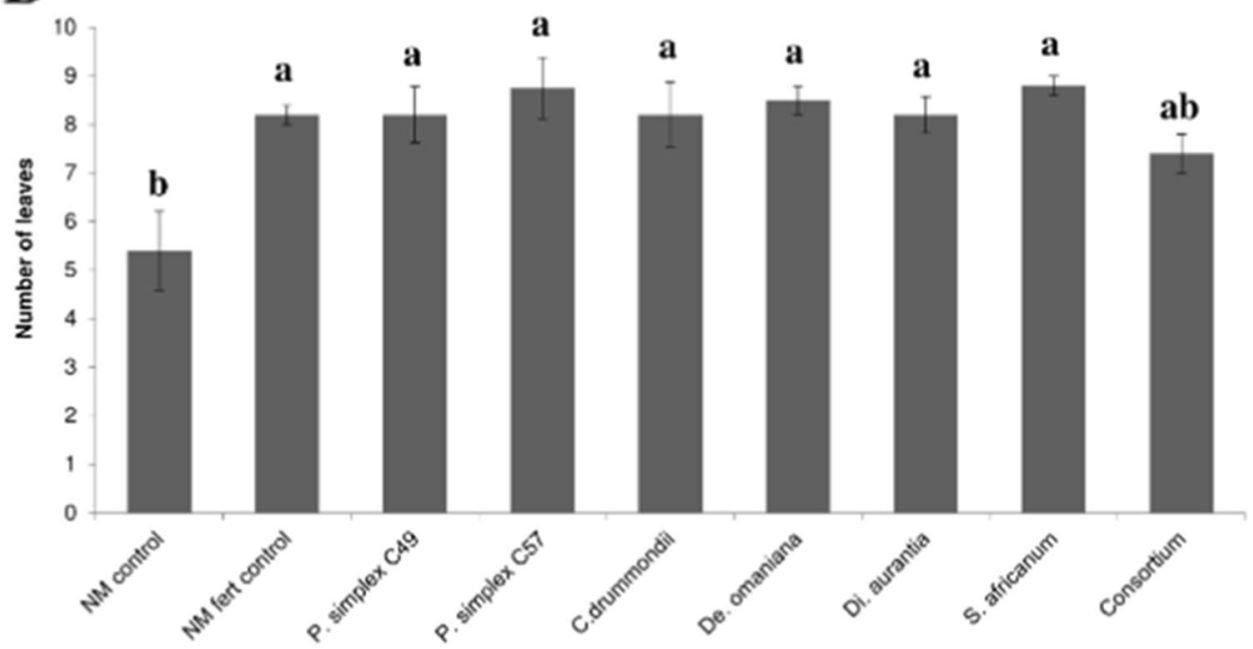


Fig. 3A). Also the number of leaves was significantly higher in all AMF treatments and in the NM-fert control plants except the AMF consortium compared with that in NM-control plants (Fig. 3B). Similar growth of mycorrhizal date palm seedlings compared to NM-fert control seedlings occurred without the application of mineral fertilizers, which may be attributed to the integration of AMF inocula into the propagation process. Inoculation with $S$. africanum even resulted in better growth, as reflected in total leaf length, compared to the NM-fert control. Thus, by introducing AMF early in the propagation process, plants grew better without the need for additional fertilizers. The two AMF species that showed the greatest effect on total leaf length, Di. aurantia and S. africanum, were originally recovered from date palm plantations (Symanczik et al. 2014b) and might have been specially adapted to interact with date palms.

The results are in accordance with previous studies investigating the interaction of AMF and date palms (Anli et al. 2020a, b; El Kinany et al. 2019). Tissue-cultured date palm seedlings inoculated with a commercial AMF inoculum showed enhanced growth, and mycorrhizal seedlings grew better without fertilizer than non-mycorrhizal fullyfertilized control seedlings (Shabbir et al. 2011), which is in accordance with these results. Similarly, Baslam et al. (2014) observed that inoculation of date palm seedlings with Rhizophagus intraradices increased leaf area, root length and shoot and root dry weight. Meddich et al. (2018) have also shown that shoot area and shoot dry weight was increased when seedlings were inoculated with different AMF species or with a native AMF complex isolated from a date palm grove in Morocco.

Date palms are commonly propagated by tissue culture techniques. After in-vitro plant establishment, the seedlings are transferred to artificial growth substrates (peat, vermiculite) that lack AMF. At this stage, mineral fertilizers are used to increase seedling growth. After being transplanted into the field, it is difficult for date palms to establish AMF symbiosis due to the low infect ion potential of most desert soils (Requena et al. 2001) and sometimes due to the high amounts of fertilizer added to the nutrient deficient soils (Smith and Read 2008). If date palm seedlings could established AMF symbiosis prior to being transplanted into the field, the high input rates of mineral fertilizers could be reduced, while achieving the same growth and yield, as shown for oil palms (Schultz 2001). Another problem related to field transplantation is the low survival rate of date palm seedlings (Zaid and De Wet 2002). Integration of AMF into the propagation process might improve the low success rates, as shown in oil palms, in which survival rate increased from $55 \%$ for non-mycorrhizal oil palm seedlings to $83 \%$ and $100 \%$ for mycorrhizal oil palm seedlings (Schultz 2001).

\subsection{Growth performance of inoculated P. cineraria}

Application of AMF inocula improved the germination and survival of $P$. cineraria during seedling establishment (Table 2). Germination and survival was considerably reduced, to a varying extent, for NM-control treatments, while many more seeds germinated in the mycorrhizal treatments, except for consortium 2 (C. drummondii and De. omaniana), which had a germination rate of $38 \%$. In addition, all mycorrhizal seedlings survived in contrast to almost all control treatments (Table 2). The growth of $P$. cineraria was significantly affected by AMF inoculation $(\mathrm{F}(14,87)=4.165, \mathrm{P}<0.001)$. After 3 months of growth, seedling height was significantly enhanced in 9 of the 11 mycorrhizal treatments compared with that in all control treatments (Fig. 2b and Fig. 4). Among these, inoculation with $S$. africanum and the consortium 4, which included most of the single strains, achieved the highest shoot length.

The application of AMF under nursery conditions has been successfully demonstrated for a range of plants including vegetables, spices, fruit crops, tropical plantation crops as well as ornamental crops and trees (Azcón-Aguilar and Barea 1997, Koltai et al. 2008, Chapdelaine et al. 2008, Baum et al. 2015, Symanczik et al. 2017). Huante et al. (2012) who performed experiments with six tree species reported that AMF inoculation significantly increased the tree growth, especially of slow growing tree species. Also Salto et al. (2020) observed improved growth and increased drought tolerance of Prosopis alba inoculated with native AMF under nursery conditions. Similarly, Kapulnik et al. (2010) and Habte et al. (2001) reported about enhanced growth and field performance of Olea europea L. and Acacia $k o a$ after AMF nursery inoculation. Accelerated growth and improved plant health and nutrition of mycorrhized plants can thus help to decrease the growth period under nursery conditions. In addition, inoculation with native versus exotic AMF species should be favored as recently reviewed by Berutti et al. (2016) who summarized the advantages of using native AMF inoculants over the application of exotic ones. Similarly, Requena et al. (2001) and Caravaca et al. (2003) reported about better field establishment of native shrubs after inoculation with native AMF species in studies to restore degraded Mediterranean ecosystems. In this context, S. africanum, which best promoted plant growth in both experiments, represents a promising candidate to be used for inoculation approaches. Also consortium 4, resulting in best growth performance of $P$. cineraria, can be recommended especially since the application of AMF consortia over single-strain inocula should be favoured according to the metaanalysis of Hoeksema et al. (2010), which indicate a higher plant response after inoculation with multiple AMF species.

However, there are some prerequisites to integrate AMF as biofertilizers into largescale agricultural and revegetation 


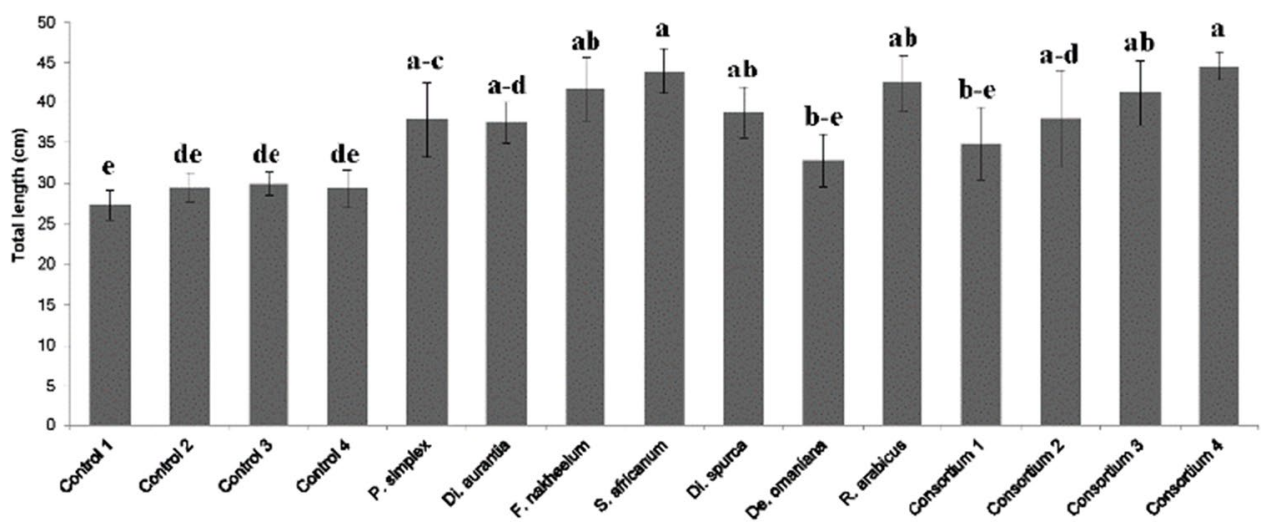

Fig. 4 Impact of inoculation with different arbuscular mycorrhizal (AM) fungal species on the height of Prosopis cineraria seedlings 3 months after sowing compared with the growth of non-mycorrhizal controls: microbial wash (control 1), autoclaved inoculum carrier (control 2), microbial wash and autoclaved inoculum carrier (control 3 ), and negative control (control 4). In addition to inoculation with single AMF species, four consortia were used as inocula: consortium
1 (Pervetustus simplex strain C49 and C56), consortium 2 (Claroideoglomus drummondii and Desertispora omaniana), consortium 3 (Septoglomus africanum and De. omaniana), and consortium 4 (P. simplex strain C49, C. drummondii; S. africanum, and De. omaniana). Different letters above bars indicate significant differences according to Tukey's honest significant difference test $(\mathrm{P} \leq 0.05)$. Data represent means $+\operatorname{SE}(n=3-13)$ programs (Koltai 2010, Igiehon and Babalola 2017). The first is the availability of mass production procedures for selected strains of AMF (Vosátka et al. 2013, Berutti et al. 2016). The second is the availability of suitable, preferably local carriers (Barea et al. 1993; Kapulnik et al. 1994; Douds et al. 2006). Moreover, strict quality control is essential to ascertain the absence of soil-borne pathogens. To fulfill these prerequisites, cooperation with industrial partners could be strived to enable AMF to become part of the sustainable management of this region. Alternatively, also farmers should be encouraged to autonomously produce their AMF inocula starting either from a native culture collection if available or from local soils (Symanczik et al. 2018).

\section{Conclusion}

In this study, native AMF from agricultural and natural habitats in the Southern Arabian Peninsula were isolated, propagated, and identified. Some of the AMF strains that were functionally evaluated represent good candidates for biofertilizers, due to their ability to enhance the growth of two local plants, $P$. dactylifera and $P$. cineraria. Considering the statistical results, the following strains were the most promising ones and resulted in better growth performance than NM-control treatments: C. drummondii (strain F41), Di. aurantia (strain G8), Di. spurca (strain K46), P. simplex (strain C49), R. arabicus (strain F80), S. africanum (strain G14), S. nakheelum (strain G90), consortium 3, and consortium 4. It is worth mentioning that the superior growth of plants inoculated with $S$. africanum (strain G14) was consistent in both experiments. This study is an important step towards the integration of native AMF into sustainable agriculture and revegetation programs in the Arabian Peninsula and may serve as a model approach for other arid lands.

Acknowledgements This work was supported by the Oman Ministry of Agriculture, Fisheries and Water Resources; Oman Botanic Garden; University of Basel; the Polish National Centre of Science; the r4d program, the Swiss Programme for Research on global Issues for Development, a partnership of the Agency for Development and Cooperation and the Swiss National Science Foundation with the r4d project "Application of organic bio-fertilizer technology to improve the sustainability of date palm production and cultivation" under grand number IZ07Z0_160904.

Funding Open access funding provided by Research Institute of Organic Agriculture. This work was partly funded by the r4d program, the Swiss Programme for Research on global Issues for Development, a partnership of the Agency for Development and Cooperation and the Swiss National Science Foundation with the r4d project "Application of organic bio-fertilizer technology to improve the sustainability of date palm production and cultivation" under grand number IZ07Z0_160904; the Technical Cooperation Program (2008-2014) between Oman Ministry of Agriculture, Fisheries and Water Resources and University of Basel "Isolation, Efficiency Assessment and Molecular Identification of AMF Strains from Omani Soils".

Data and/or Code availability 'Not applicable' for that section.

\section{Declarations}

Ethical approval Ethical approval was waived by the local Ethics Committee of Research Institute of Organic Agriculture (FiBL), Ackerstrasse 113, 5070 Frick, Switzerland.of the retrospective nature of the study and all the procedures being performed were part of the routine care. 
Consent to participate Informed consent was obtained from all individual participants included in the study.

Conflicts of interest/competing interests The authors declare that they have no conflict of interest.

Open Access This article is licensed under a Creative Commons Attribution 4.0 International License, which permits use, sharing, adaptation, distribution and reproduction in any medium or format, as long as you give appropriate credit to the original author(s) and the source, provide a link to the Creative Commons licence, and indicate if changes were made. The images or other third party material in this article are included in the article's Creative Commons licence, unless indicated otherwise in a credit line to the material. If material is not included in the article's Creative Commons licence and your intended use is not permitted by statutory regulation or exceeds the permitted use, you will need to obtain permission directly from the copyright holder. To view a copy of this licence, visit http://creativecommons.org/licenses/by/4.0/.

\section{References}

Al-Shahib W, Marshall RJ (2003) The fruit of the date palm: its possible use as the best food for the future? Int J Food Sci Nutr 54(4):247-259

Al-Yahya'ei MN, Oehl F, Vallino M et al (2011) Unique arbuscular mycorrhizal fungal communities uncovered in date palm plantations and surrounding desert habitats of Southern Arabia. Mycorrhiza 21(3):195-209

Anli M, Symanczik S, El Abbassi A et al (2020a) Use of arbuscular mycorrhizal fungus Rhizoglomus irregulare and compost to improve growth and physiological responses of Phoenix dactylifera 'Boufgouss.' Plant Biosyst 155(4):763-771

Anli M, Baslam M, Tahiri A et al (2020b) Biofertilizers as strategies to improve photosynthetic apparatus, growth, and drought stress tolerance in the date palm. Front Plant Sci 11:516818

Antunes PM, Koch AM, Morton JB et al (2011) Evidence for functional divergence in arbuscular mycorrhizal fungi from contrasting climatic origins. New Phytol 189(2):507-514

Azcón-Aguilar C, Barea JM (1997) Applying mycorrhiza biotechnology to horticulture: significance and potentials. Sci Hortic 68(1-4):1-24

Azcón-Aguilar CJ, Palenzuela A, Roldán S et al (2003) Analysis of the mycorrhizal potential in the rhizosphere of representative plant species from desertification-threatened Mediterranean shrublands. Appl Soil Ecol 22(1):29-37

Bano SA, Uzair B (2021) Arbuscular Mycorrhizal Fungi (AMF) for Improved Plant Health and Production. In: Kaushal M, Prasad $\mathrm{R}$ (eds) Microbial Biotechnology in Crop Protection. Springer, Singapore

Barea JM, Azcón R, and Azcón-Aguilar C (1993) Mycorrhiza and crops. In. Advances in Plant Pathology, vol. 9: Mycorrhiza Synthesis, ed. I. C. Tommerup, 167-189. Academic Press, London

Barea JM, Palenzuela J, Cornejo P et al (2011) Ecological and functional roles of mycorrhizas in semi-arid ecosystems of Southeast Spain. J Arid Environ 75(12):1292-1301

Baslam M, Qaddoury A, Goicoechea N (2014) Role of native and exotic mycorrhizal symbiosis to develop morphological, physiological and biochemical responses coping with water drought of date palm, Phoenix dactylifera. Trees Struct Funct 28:161-172

Bauer JT, Koziol L, Bever JD (2020) Local adaptation of mycorrhizae communities changes plant community composition and increases aboveground productivity. Oecologia 192:735-744
Baum C, El-Tohamy W, Gruda N (2015) Increasing the productivity and product quality of vegetable crops using arbuscular mycorrhizal fungi: a review. Scientia Horticulturae 187:131-141

Berutti A, Lumini E, Balestrini R, Bianciotto V (2016) Arbuscular mycorrhizal fungi as natural biofertilizers: let's benefit from past successes. Front Microbiol 6:1559

Blaszkovski J, Kozłowska A, Crossay T et al (2017) A new family, Pervetustaceae with a new genus, Pervetustus, and P. simplex sp. nov. (Paraglomerales), and a new genus, Innospora with I. majewskii comb. nov. (Paraglomeraceae) in the Glomeromycotina. Nova Hedwigia 105(14):397-410

Caravaca F, Barea JM, Palenzuela J et al (2003) Establishment of shrub species in a degraded semiarid site after inoculation with native or allochthonous arbuscular mycorrhizal fungi. Appl Soil Ecol 22(2):103-111

Chapdelaine A, Dalpé Y, Hamel C et al (2008). Arbuscular mycorrhizal inoculation of ornamental trees in nursery. Mycorrhiza Works; Feldmann F, Kapulnik Y, Baar J (Eds), 46-55

Douds DD, Nagahashi G, Pfeffer PE et al (2006) On-farm production of AM fungus inoculum in mixtures of compost and vermiculite. Biores Technol 97(6):809-818

El Kinany S, Achbani E, Faggroud M et al (2019) Effect of organic fertilizer and commercial arbuscular mycorrhizal fungi on the growth of micropropagated date palm cv. Feggouss. J Saudi Soc Agric Sci 18(4):411-417

Fisher M, Membery DA (1998) Climate. In: Ghazanfar SA, Fisher M (eds) Vegetation of the Arabian Peninsula. Springer, Dordrecht, pp 5-38

Gai JP, Christie P, Feng G, Li XL (2006) Twenty years of research on community composition and species distribution of arbuscular mycorrhizal fungi in China: a review. Mycorrhiza 16(4):229-239

Glennie KW, Singhvi AK (2002) Event stratigraphy, paleoenvironment and chronology of SE Arabian deserts. Quatern Sci Rev 21(7):853-869

Habte M, Miyasaka SC and Matsuyama DT (2001). Arbuscular mycorrhizal fungi improve early forest-tree establishment. Plant Nutrition: Food Security and Sustainability of Agroecosystems Through Basic and Applied Research; Horst WJ, Schenk MK, Bürkert A et al (Eds), 644-645

Hoeksema JD, Chaudhary VB, Gehring CA et al (2010) A meta-analysis of context-dependency in plant response to inoculation with mycorrhizal fungi. Ecol Lett 13(3):394-407

Huante P, Ceccon E, Orozco-Segovia A et al (2012) The role of arbuscular mycorrhizal fungi on the early-stage restoration of seasonally dry tropical forest in Chamela. Mexico Revista Árvore 36(2):279-289

Igiehon NO, Babalola OO (2017) Biofertilizers and sustainable agriculture: exploring arbuscular mycorrhizal fungi. Appl Microbiol Biotechnol 101(12):4871-4881

Jeffries P, Gianinazzi S, Perotto S et al (2003) The contribution of arbuscular mycorrhizal fungi in sustainable maintenance of plant health and soil fertility. Biol Fertil Soils 37(1):1-16

Kapulnik Y, Heuer B, Patterson NA et al (1994) Stunting syndrome in peanuts and agronomic approaches for its release. Symbiosis 16(3):267-278

Kapulnik Y, Tsror L, Zipori I et al (2010) Effect of AMF application on growth, productivity and susceptibility to Verticillium wilt of olives grown under desert conditions. Symbiosis 52(2):103-111

Koch AM, Antunes PM, Barto EK et al (2011) The effects of arbuscular mycorrhizal (AM) fungal and garlic mustard introductions on native AMF diversity. Biol Invasions 13(7):1627-1639

Koide R, Elliott G (1989) Cost, Benefit and Efficiency of the VesicularArbuscular Mycorrhizal Symbiosis. Funct Ecol 3(2):252-255

Koltai H (2010) Mycorrhiza in floriculture: difficulties and opportunities. Symbiosis 52(2-3):55-63 
Koltai H, Meir D, Resnick N et al (2008). Application of Mycorrhiza to Ornamental Horticulture Crops. Mycorrhiza Works; Feldmann F, Kapulnik Y, Baar J (Eds), 39-46

Koziol L, Schultz PA, House GL et al (2018) The Plant Microbiome and Native Plant Restoration: The Example of Native Mycorrhizal Fungi. Bioscience 68(12):996-1006

Lekberg Y, Koide RT (2008) Effect of soil moisture and temperature during fallow on survival of contrasting isolates of arbuscular mycorrhizal fungi. Botany 86(10):1117-1124

Marulanda A, Porcel R, Barea JM, Azcón R (2007) Drought tolerance and antioxidant activities in lavender plants colonized by native drought-tolerant or drought-sensitive Glomus species. Microb Ecol 54(3):543-552

Meddich A, Ait El Mokhtar M, Bourzik W et al (2018) Optimizing Growth and Tolerance of Date Palm (Phoenix dactylifera L.) to Drought, Salinity, and Vascular Fusarium-Induced Wilt (Fusarium oxysporum) by Application of Arbuscular Mycorrhizal Fungi (AMF). In: Giri B, Prasad R, Varma A (eds) Root Biology. Soil Biology 52. Springer, Cham

Mummey DL, Antunes PM, Rillig MC (2009) Arbuscular mycorrhizal fungi pre-inoculant identity determines community composition in roots. Soil Biol Biochem 41(6):1173-1179

Nzanza B, Marais D, Soundy P (2012) Response of tomato (Solanum lycopersicum L.) to nursery inoculation with Trichoderma harzianum and arbuscular mycorrhizal fungi under field conditions. Acta Agric Scand Sect B Soil Plant Sci 62(3):209-215

Patzelt A (2015) Synopsis of the Flora and Vegetation of Oman, with Special Emphasis on Patterns of Plant Endemism. Abhandlungen der Braunschweigischen Wissenschaftlichen Gesellschaft, 282-317.

Patzelt A, Al Farsi K, Morris L, Spalton A (2009) The Oman botanic garden (2): collections policy, nursery construction, expanded plant production and initial tree translocation. Sibbaldia 7:83-97

Patzelt A, Morris L, Al Harthi L et al (2008) The Oman botanic garden (1): the vision, early plant collections and propagation. Sibbaldia 6:41-77

Qin M, Shi G, Zhang Q et al (2019) Arbuscular mycorrhizal fungi serve as keystone taxa for revegetation on the Tibetan Plateau. J Basic Microbiol 59(6):609-620

Ren L, Wang B, Yue C et al (2019) Mechanism of application nursery cultivation arbuscular mycorrhizal seedling in watermelon in the field. Ann Appl Biol 174:51-60

Requena N, Jeffries P, Barea JM (1996) Assessment of natural mycorrhizal potential in a desertified semiarid ecosystem. Appl Environ Microbiol 62(3):842-847

Requena N, Perez-Solis E, Azcón-Aguilar C et al (2001) Management of indigenous plant-microbe symbioses aids restoration of desertified ecosystems. Appl Environ Microbiol 67(2):495-498
Salto CS, Sagadin MB, Luna CM et al (2020) Interactions between mineral fertilization and arbuscular mycorrhizal fungi improve nursery growth and drought tolerance of Prosopis alba seedlings. Agroforest Syst 94:103-111

Schultz C (2001) Effect of (vesicular-) arbuscular mycorrhiza on survival and post vitro development of micropropagated oil palms (Elaeis guineensis Jacq.). PhD diss., University of Göttingen

Schwartz MW, Hoeksema JD, Gehring CA et al (2006) The promise and the potential consequences of the global transport of mycorrhizal fungal inoculum. Ecol Lett 9(5):501-515

Shabbir G, Dakheel AJ, Brown GM and Rillig MC (2011) Potential of Arbuscular Mycorrhizal Technology in Date Palm Production. In Date Palm Biotechnology, ed. S. M. Jain, J. M. Al-Khayri, and D. V. Johnson, 449-479. London, New York: Springer Dordrecht

Smith SE and Read D (2008) Mycorrhizal Symbiosis. 3rd ed. Academic Press

Swofford DL (2001) PAUP*. Phylogenetic Analysis Using Parsimony (*and Other Methods) 4.0.b5. Sunderland: Sinauer Associates

Symanczik S, Błaszkowski J, Chwat G et al (2014a) Three new species of arbuscular mycorrhizal fungi discovered at one location in a desert of Oman: Diversispora omaniana, Septoglomus Nakheelum and Rhizophagus arabicus. Mycologia 106(2):243-259

Symanczik S, Błaszkowski J, Koegel S et al (2014b) Isolation and identification of desert habituated arbuscular mycorrhizal fungi newly reported from the Arabian Peninsula. J Arid Land 6(4):488-497

Symanczik S, Courty PE, Boller T et al (2015) Impact of water regimes on an experimental community of 4 desert arbuscular mycorrhizal fungal (AMF) species, as affected by the introduction of a nonnative AMF species. Mycorrhiza 25(8):639-647

Symanczik S, Gisler M, Thonar C et al (2017) Application of mycorrhiza and soil from a permaculture system improved phosphorus acquisition in naranjilla. Front Plant Sci 8:1263

Symanczik S, Bouamri B, Rachidi F and Mäder P (2018) Mycorrhizal fungi as natural bio-fertilizers: How to produce and use. Fertiledatepalm Technical Note. Research Institute of Organic Agriculture (FiBL) and École National d'Agriculture (ENA), Frick, Switzerland and Meknes, Morocco

Vosátka A, Látr M, Gianinazzi S, Albrechtová J (2013) Development of arbuscular mycorrhizal biotechnology and industry: current achievements and bottlenecks. Symbiosis 58:29-37

Zaid A, de Wet PF (2002) Date Palm Propagation. In: Zaid A (ed) Date Palm Cultivation. FAO, Rome, pp 74-106

Publisher's note Springer Nature remains neutral with regard to jurisdictional claims in published maps and institutional affiliations. 